\title{
Scriptures, science and mythology: Astronomy in Indian cultures
}

\author{
Rajesh Kochhar \\ Indian Institute of Science Education and Research, \\ Mohali, Sector 26, Chandigarh 160019, India \\ email: rkochhar2000@yahoo.com
}

\begin{abstract}
Human beings are born astronomers. Ever since they learnt to walk upright they have looked at the sky and wondered. The sky has remained the same but not its meaning. We can distinguish between three phases in the history of humankind's relationship with its cosmic environment: (i) propitiatory phase; (ii) negotiatory phase; and the current (iii) sky-asan-object explanatory, phase. My concern here is to discuss the interplay between astronomy and culture in general in the Indian context. Much of the discussion belongs to the negotiatory phase. More specifically I discuss how in the formative era, sacred texts influenced astronomy, how these texts themselves were modified under the influence of new scientific developments, and how mythology was upgraded to keep pace with science.
\end{abstract}

Keywords. Cosmic environment, sacred texts, mythology, cultural astronomy, cyclic time

\section{Introduction}

Human beings are born astronomers. Ever since they learnt to walk upright they have looked at the sky and wondered. The sky has remained the same but not its meaning. We can distinguish between three phases in the history of humankind's relationship with its cosmic environment: (i) propitiatory phase; (ii) negotiatory phase; and the current (iii) sky-as-an-object explanatory phase. Each of these phases leads to and coexists with the next.

To begin with, sky was seen as home to capricious divinities who were to be feared and propitiated. As time progressed, human beings felt more secure and became intellectually more alert. Earlier awe made way for curiosity. Skies were now scanned for discovering patterns in the behaviour of the divinities. The knowledge so gained was put to practical use and employed to establish a negotiatory relationship with the celestial bodies. The third phase began four centuries ago with Galileo's telescope. Sky was inhabited by objects and not divinities. The cosmic environment was now subjected to scientific scrutiny with a view to discovering and testing laws of nature. Earlier astronomy had measured angles; now it could talk of distances. The sky had acquired depth. There is an interesting correlation between the world geopolitics and our view of the cosmos, which does not seem to have been noticed before. For a very long time, the model universe had a centre. The pride of place first belonged to the earth and then to the Sun. Even when galaxies were discovered our Galaxy was believed to be the largest. It is in relatively recent times, in the post-World War II era, that the universe has truly become egalitarian. Interestingly, this cosmic scheme has been mimicked on the earth as well. When the universe was centric, the Earth, or parts thereof, also had a power centre, be it local or on a larger scale. The Copernican principle now applies, at least in principle, to the Earth as well. Is this a coincidence? Or is it that our perception of the cosmos influences the scheme of things on the Earth just as this perception itself is fashioned by the situation on Earth? 
My concern here is to discuss the interplay between astronomy and culture in general in the Indian context. Much of the discussion belongs to the negotiatory phase described above. I have advisedly used culture in the plural in the title. This is not so much to describe the scope of this review as to draw attention to its limitations. For a number of reasons, discussed in a different context elsewhere, most of the world attention on India's past has focused on Sanskrit texts and the associated culture (Kochhar 2008a,b). We have no clues whatever to the astronomical knowledge prevalent during the various phases of the vast Harappan archaeological tradition the roots of which go back to the very beginning of agriculture and animal husbandry, in $7000 \mathrm{BCE}$, in what is now Baluchistan. Also the astronomical knowledge residing in the fields rather than in the archives and especially belonging to communities officially termed scheduled tribes needs to be examined in depth. New scholarship must go beyond the Sanskrit India.

\section{Source material}

Any discussion that involves ancient India must take note of the nature and limitations of the source material available. Scripts (Kharoshthi, Brahmi) were introduced into India about 3rd century BCE or somewhat earlier for writing Prakrit languages derived from Sanskrit. Script for Sanskrit itself, the language of Hindu scriptures, was adopted much later. Writing material came from plants or trees and had a short life. Paper was not introduced into India till about 8th century. The Vedic texts were in any case forbidden to be written†. Ancient Indian intellectual tradition was oral. Texts were in the custody of specialist caste groups who memorized them and transmitted them to the next generation by word of mouth. The extant texts would have been supplemented with explanatory 'notes' to serve an immediate purpose. What was not considered worth preserving at any point in time was lost for ever. Also, it is not possible to assign firm dates to any early event or development.

It is therefore not possible to construct a connected account about any aspect of early Indiaf. We must cull relevant information from a variety of literary sources: Vedic texts; Puranas and the epics Ramayana and Mahabharata; Buddhist and Jain sources, including those from outside India; astronomy texts proper. The most important of these is the Vedic corpus, comprising priestly books composed by a large number of authors over a long period of time, which could be as much as two thousand years, say from 1700 BCE to zero CE and later (Kochhar 2000). The importance of the Vedic texts lies in the fact that scrupulous care was taken to preserve them in their original form. They are thus truly representative of the time of their composition even if that time is largely indeterminable.

The pride of place in the Vedic corpus goes to the oldest and the stand-alone text, Rgveda, containing about ten thousand stanzas. According to Kochhar (2000) it was composed over a period extending say from $1700 \mathrm{BCE}$ to $900 \mathrm{BCE}$, although its earliest portions probably contain memories of still earlier time 9 . The Vedic texts constitute the heritage of Hinduism. The youngest texts, like Manavadharmasastra, or Manusmrti, which could be as recent as zero CE plus minus, represent transition to Hinduism proper. The texts associated with Hinduism as practiced are the Puranas and the two epics, Ramayana and Mahabharata. They were narrated to the public at large and used to

$\dagger$ In the following Sanskrit words have been written by omitting diacritical marks.

$\ddagger$ Western scholarship especially during the colonial period tended to deny antiquity or originality to ancient India. As a backlash, many researchers have tended to unduly stretch the chronology backwards.

I Some other texts, though closed later, may contain some older matter. 
be recast to suit the prevailing requirements of the narrators as well as the listeners. Significantly, additions were made, but no deletions. In addition there are scientific corpus dealing with astronomy (as also with health care, that is Ayurveda) which underwent deletion as well as addition.

\section{Textual astronomy}

There are a few stray astronomical references in the Rgveda, but for our purposes the more useful is the Yajurveda which is a manual for actual performance of ritual. Since the ritual seeks to enlist divine support for human endeavours, astronomical timing is the most important part of it. Moon's position every night was marked with respect to bright star or star group that was seen near it. These 28 or 27 stars, known as naksatra, were enumerated beginning with Krttika (Pleiades) which then described the Spring equinox $\uparrow$. There is a solitary Vedic text, Vedanga Jyotisa, devoted exclusively to astronomy. It is the least understood of the whole corpus, partly because it was overtaken by developments. The oldest portions could be as old as 1400 BCE. Interestingly it deals only with the movements of the Sun and the Moon. Zodiacal signs and week days are conspicuous by their absence. They would be introduced into India about $100 \mathrm{BCE}$, as part of interaction with the post-Alexandrian, post-Asokan Greco-Babylonian world. Greek astro-text was translated into Sanskrit in 149 by Yavanesvara. It was versified in 269 by Sphujidhvaja under the title Yavanajataka (Pingree 1959). The versification was a significant development, because it signifies assimilation of Greco-Babylonian elements into Indian tradition. The Vedic astronomical tradition remained extant even after the introduction of Yavana texts. A Buddhist Sanskrit text, known as Sardulakaranavadana and dated about fourth century still adheres to Vedic astronomy.

A pioneering name in the systematisation of the post-Vedic, post Yavanajataka, astronomy was Aryabhata (b. 476), whose influential text Aryabhatiyam appeared in 499.Indian mathematical astronomy, which we may call Siddhantic (since the astronomical texts were called Siddhanta, proven in the end), focused on calculating geo-centric planetary orbits and especially the lunar and solar eclipses. From 6th century till Kepler's time, Indian astronomers were probably the only ones who could calculate eclipses with any degree of accuracy. The unbroken tradition was alive till as recently as 19 th century. A Tamil astronomer computed for John Warren, a French astronomer in the service of British East India Company, the lunar eclipse of 1825 May 31-June 1 with an error of +4 minutes for the beginning, -23 minutes for the middle, and -52 minutes for the end (Neugebauer 1983).

Indian astronomers did not know of precession of equinoxes. Accordingly the match between the observed sky and the computed orbits would disappear in a few centuries. Occasionally, a brilliant astronomer appeared on the scene and reworked the mathematics. Remarkably although the physical goal was the same different astronomers ended up setting up and solving different equations. Mathematics was a tool for planetary calculations. There are very few full-time mathematicians in the Indian tradition (Kochhar 1993).

After this brief review of literature, we shall now discus the interplay between various cultural streams.

$\dagger$ Later lists, prepared about 500, would begin with Asvini, that is Beta Arietis, in honour of the current Spring equinox. 


\section{Cosmic order and human ethics}

The eternity around us has stood in sharp contrast to the short time-span of the human beings themselves. This chasm has been sought to be bridged by denying death finality. The burial cultures have postulated the physical rising of the dead, while the cremation cultures have distinguished between the body and the soul, and spoken of the indestructibility of the latter. There is a beautiful concept linking the divine with the human that goes back to the joint Indo-Iranian times. Called rta in the Rgveda and arta (or asa) in the Avesta, it refers to the cosmic order, not in the sense of impersonal laws of nature as ascertained from the outside, but as an example of righteous cosmic conduct which the humans should emulate.

The Sun, Moon and other geocentric planets dutifully and predictably orbit around the earth. (Their predictability was a source of comfort, in contrast to the sudden ill-omened appearance of comets, meteors, etc.) The laws regulating the behaviour of these divinities are inbuilt into the system. But similar regulation of human conduct can come only from an explicit prescription of a code of ethical conduct. Emphasis on rta / arta is far more pronounced in the Avesta than Rgveda. To bring the terrestrial and the celestial closer together the Vedic people assigned the attributes of one to the other. Planets return to their place in the sky; so do seasons on the earth. But human beings are born and die. In analogy with the planets, human beings should also have continuity. To achieve this, the concept of reincarnation was introduced. But in a certain sense planets are condemned to a life of incessant motion. An endless cycle of birth and death would be a punishment rather than a boon. Therefore the concept of what we may call truncated eternity was introduced, under the name moksa or nirvana, whereby a soul is liberated from the constraints of future birth.

\section{The cyclic time}

Far more important were the human attributes assigned to the gods. The concept of age, birth and death was introduced for the cosmos as a whole, and a cosmic chronology in the form of the yuga system was constructed by suitably scaling up the human calendar. The eternity of the planetary orbits was generalised to set up an oscillating universe without beginning or end.

For the mathematically oriented brave hearts, the technical details are explained in the Appendix. Here we may notice some important features of the scheme. In the Vedic period, a year was taken to comprise 12 months and 360 days. Multiply these two numbers to get $360 \times 12=4320$. Now, suffix this number with the requisite number of zeroes to produce long structured time-spans. The basic unit is a mahayuga (mega-age):

$$
1 \text { mahayuga }=4.32 \text { million years. }
$$

A still bigger time-span, Brahma's twelve-hour day (or night), or a kalpa, is defined as equal to 1000 mahayugas:

1 Brahma's day $=4.32$ billion years.

Ancient Indians were probably the only people talking of such large numbers and of the endlessness of the universe. These numbers have been noticed by modern cosmologists in their textbooks as the cosmological timescales indeed turn out to be of the order of billions of years. mahayuga, in turn, is composed of four ages or yugas: satya or krta; treta; dvapara; and kali. The scheme has some interesting attributes:

(a) Virtue decreases down the ages in the ratio 4:3:2:1.

(b) Duration of the individual ages also decreases in the same ratio. 
(c) Kaliyuga is thus the shortest.

(d) We are currently in the kaliyuga.

The scheme must have been found very attractive because it was used in entirely different contexts with the same terminology. These long ages were employed in astronomy. The terminology of the four yugas was also employed by the Puranas to periodise political history going back about 100 generations. This multi-use has caused much contemporary confusion.

The scheme was formulated in the kaliyuga itself. It is significant that the present age was postulated to be the kaliyuga. We are now in the worst of times. Things can only improve. Imagine, if we had been placed in any of the earlier yugas, things would have had to deteriorate further before they could improve. It is thus an inherently optimistic scheme. During the movement against the British rule in India, the dark kaliyuga making way for satyayuga was repeatedly invoked to enhance nationalist consciousness.

\section{Sacred texts influence science}

Use of early astronomical data in the ritual profoundly influenced the later course of astronomical developments. The yuga system with its nomenclature was borrowed by the astronomers. Thus the Surya Siddhanta would say that there were 146,568 revolutions of Saturn in a mahayuga, implying an orbital period of 29.4743 years. Interestingly, Aryabhata set his kalpa equal to 1008 mahayugas (instead of the Vedic 1000). Since 1008 is divisible by seven, all kalpas, each 4.32 billion years apart will begin on the same day of the week. Some farsight indeed! He deviated from the Vedic yuga scheme in another way also. He split a mahayuga into four equal parts.

Like the Vedic anthologies, astronomical texts were composed in verse, so that an astronomer had to be a Sanskrit poet first. Constraints of metre forced astronomers to use synonyms and take recourse to allusions. This introduced ambiguity at places. More importantly only conclusions were preserved and not the arguments leading to them. Generally speaking there was a tendency to present astronomical results as revealed knowledge rather than deduced. Interestingly although India invented the decimal numerical system, astronomical texts, bound by the self-imposed constraint of metrical poetry, present numbers as words, at times leading to mis-reading and mis-interpretation.

Aryabhata believed in the spin of the Earth and said so in his work. This however never became a part of the mainstream. He was severally criticized for this by his 'adversaries'. Even later astronomers belonging to his own school felt so embarrassed that they tried to change a word here and there in his work to convey the impression that the great master like everybody else took the Earth to be non-spinning. Interestingly the Skanda Purana (1.1.31.71) describes the Earth as revolving like a bhramarika (spinning top). Here we have an example of a 'religious' text subscribing to a scientific view even though it was not a commonplace. Today we give great credit to Aryabhata for his belief in Earth's spin. But it is important to keep in mind that our source of knowledge is his critics who were putting Aryabhata's lapses on record. As an analogy, we may note that we know about the deeds of revolutionaries fighting for India's freedom from the charge sheets filed against them by the colonial government $†$.

If astronomy had followed a prose tradition (as was the case with post-Vedic Upanishads) some later scholars could have revived and expanded on Aryabhata's hypothesis. Indian astronomers were not aware of the precession of equinoxes. A creative astronomer

$\dagger$ As a belated compensation Aryabhata's glorifiers now falsely credit him with belief in heliocentrism. 
would adjust his parameters so that his computed planetary orbits matched the observations. With the passage of time the match would disappear necessitating the arrival of a new mathematician astronomer. Interestingly while astronomic texts are known by the name of their authors, their elements were used to upgrade old texts which were claimed to be divine in origin. This was done to enhance the value of these works in the astrological market. It is noteworthy that Buddha was against astrology. As long as Buddhism held sway astronomy went in decline. It is only on resurgence of Hinduism that astronomy revived. By the time Buddhism was exported, astrology had become part of it.

Old astronomical knowledge remains a living tradition even if its role is not so obvious. Spring and Autumn equinoxes as well as Winter solstice (but not the Summer solstice) are still celebrated as religious festivals $\dagger$.

Traditional almanacs in current use still use old prescriptions. They have accumulated an error of 23 days due to precession of equinoxes, but nobody seems to mind. The reason is that phenomena like ingress into a zodiacal sign are not visible to the eye. Since eclipses can be timed now with great accuracy, their computation is not done traditionally but on the basis of modern algorithms. Much of the contemporary interest still centres on the astrological universe. Interest in the progress since, for some reason, extends only to black holes and the origin of the universe. This is probably so because here the difference between the layperson and the expert gets blurred. All astronomical developments in between commonly leave the laypersons rather unenthused.

\section{Science modifies sacred texts}

We have already seen how astronomical tradition was influenced by the Vedic. But the traffic was two-way. This can be seen from the treatment of eclipses. In early texts, eclipses are attributed to demon, named Rahu. Rahu is explicitly named in Atharvaveda (19.9.10). Chandogya Upanishad declares that a soul which has acquired pure knowledge is liberated from the body like the moon becoming free from Rahu (Kane 1977). Since the cause of eclipse was not known, Rahu was classified among bad omens, as in Sardulakaranavadana (Vaidya 1999). Interestingly, even within the framework of mythology attempts were made to answer critical questions. If eclipse was caused by Rahu's swallowing the sun or the moon, how did the eclipse end. The demon's head was chopped off so the the eclipsed body had an exit route. Once mathematical theory of eclipse had been propounded (499), mythology was upgraded. Rahu was promoted as a planet. Since eclipse can take place at either of two lunar nodes, another demon was needed. The headless body was now accepted as a demon in its own right, was named Ketu and twinned with Rahu. Note that Ketu was a term already in use but in non-eclipse contexts. Inadvertent backdating of new meaning of Ketu to older references has led to mis-representations. Maitrayani Upanisad mentions both Rahu and Ketu along with Sani, that is Saturn (Kane 1977). Explicit bracketing of Rahu and Ketu with a regular planet shows that this text must have been open in 500 .

Subsequently the concept of Rahu and Ketu travelled outside India also. Burma knew of Rahu as Yahu (Kochhar 1990). Interestingly, in China while Rahu stood for the ascending node, Ketu denoted the lunar apogee, an identification not known in India.

$\dagger$ Thus Spring and Autumn equinoxes are nominally honoured by nine-day celebration each, called navaratri. Makara samkranti, the Sun's ingress into Capricorn, on about 14 January, is nominally celebrated as northward turning of the Sun. Jupiter's 12-year orbital period is commemorated by the Kumbh festival, marking Jupiter's computed ingress into Aquarius. 
It is noteworthy that no religious, spiritual or revealed text or folklore has ever contradicted what the people at the time accepted as scientific knowledge. There is a basic difference between scientific tradition and the other societal traditions. Science is inherently progressive. It continually updates itself. There is no concept of frozenness associated with it. On the other hand sacred tradition or folklore remains open for a while during which it takes note of contemporaneous scientific developments. But then it becomes static and at times even may see later scientific developments antagonistically†.

\section{References}

Burgess, E. 1860, The Surya Siddhanta (reprint 2005) (Delhi: Motilal Banarsidass)

Kane, P. V. 1977, History of Dharmasastra, Vol. V (Poona : Bhandarkar Oriental Research Institute)

Kochhar, R. 1990, Quart. J. R. Astr. Soc., 31, 257

Kochhar, R. 1993, in Astronomy in India: Past, Present and Future, R. Kochhar and J. Narlikar (eds) (Pune: IUCAA)

Kochhar, R. 2000, The Vedic People: Their History and Geography (Hyderabad: Orient Longman)

Kochhar, R. 2008a, Indian Journal of Physics, 82, 1003

Kochhar, R. 2008b, Social Scientist, 36,45

Mani, V. 1975, Puranic Encyclopaedia (Delhi: Motilal Banarasidass)

Neugebauer, O. 1983, Astronomy and History: Selected Essays (New York: Springer)

Pingree, D. 1959, J. Amer. Oriental Soc., 79, 282

Vaidya, P. L. (ed.) 1999, Divyavadanam. Buddhist Sanskrit Texts 20 (Darbhanga: The Mithila Institute)

\section{Appendix: Creation chronology}

The Rgveda uses yuga in the sense of a time-span, an age, or a generation. Vedanga Jyotisha refers to a five-year yuga. Atharvaveda mentions in order 100 years, 1000 years, ayuta (10,000 years) and then two, three or four yugas. This suggests that a yuga here means an ayuta. The yuga-system as now commonly understood is set forth in the relatively late Vedic text Manusmrti (1.68-1.86), and expanded in the various Puranas.

In the Vedic times, a year comprised 12 months and 360 days. A human year was set equal to a day of the gods, so that a divine year ( $D y r$ ) would consist of 360 human years (a). The divine year in turn was used to construct an elaborate chronology.

A mahayuga or caturyuga (great age or four-age) was postulated as made up of four sub-ages or yugas: kaliyuga, dvaparayuga, tretayuga and krtayuga, with lengths in the ratio 1:2:3:4. The names are significant. The two middle ones obviously refer to the second and the third. The names of the two end yugas are taken from the game of dice, kali referring to one, and krta to four. The numbering is thus backwards, kaliyuga being the shortest and the latest.

It will be convenient to use mathematical notation to properly understand the formulation of the yuga system. A kaliyuga is said to contain 1200 Dyr. Let us denote the duration of a kaliyuga by the symbol $k$ and of a mahayuga by $m$. dvapara, treta and krta are then $2 k, 3 k$ and $4 k$ respectively, so that

$$
m=k+2 k+3 k+4 k=10 k
$$

$\dagger$ Hindu society has tended to accept modern scientific discoveries through the side door, by pretending that they were known to the ancient scriptures! 
For later reference, let us denote a krtayuga $(=4 k)$ by $s$. Then

$$
6 m=60 k=15 s
$$

We now construct a still bigger time-span called kalpa, comprising 1000 mahayugas. To complicate matters, let us introduce structure into a kalpa as follows:

$$
\begin{aligned}
1 \text { kalpa } & =1000 m \\
& =994 m+6 m \\
& =14 \times 71 m+15 s \\
& =14 \times 71 m+14 s+s \\
& =s+14(71 m+s)
\end{aligned}
$$

Let us call $71 \mathrm{~m}$ a Manvantara (Manu's interval) so called because this span is presided over by a ruler designated Manu. There are thus 14 Manus. We can now describe a kalpa in words. A kalpa begins with a dawn equal to a krtayuga. This dawn is followed in succession by 14 Manvantaras, at the end of each of which there occurs a deluge (pralaya) lasting a krtayuga. This complex scheme has perplexed many modern-day commentators. Thus, Ebenezer Burgess in his famous 1860 annotated translation of the Surya Siddhanta declared: "Why the factors fourteen and seventy - one were thus used in making up the Aeon [kalpa] is not obvious" (Burgess 1860). I think this scheme was constructed working backwards from the neat round figure of 1000 .

To sum up so far, a kalpa comprises 1000 mahayugas, with one mahayuga equaling in length ten kaliyugas. It now remains to give recognizable values to these numbers. A kaliyuga was set equal to 1200 divine years. Recalling that a divine year consists of 360 (human) years, we can express the yugas in human years:

$$
\begin{aligned}
\text { Kaliyuga } & =4 \times 32,000 \text { years } \\
\text { Mahayuga } & =4.32 \times 10^{6} \text { years } \\
\text { Kalpa } & =4.32 \times 10^{9} \text { years }
\end{aligned}
$$

Kalpa becomes the basis for constructing a chronology for Brahma, the supreme creator. A kalpa is set equal to Brahma's day or night. 360 kalpa pairs define Brahma's year, 100 years making his life-span. Currently, we are in the midst of Brahma's life. He has completed 50 years of his life. In the current kalpa seven out of the fourteen Manvantara are over, and so on. 